\title{
A TOC PERSPECTIVE TO IMPROVE THE MANAGEMENT OF COLLABORATIVE NETWORKS
}

\author{
Alexandra Tenera, António Abreu \\ New University of Lisbon \\ Quinta da Torre - 2829 Monte Caparica, PORTUGAL \\ $\underline{a b t @ f c t . u n l . p t,}, \underline{a i f a @ f c t . u n l . p t,}$
}

\begin{abstract}
Collaborative networks are typically assumed to bring clear benefits and competitive advantage to the participating members. On the other hand, since the networks are typically formed by heterogeneous and autonomous enterprises, it is natural that each member has its own culture and set of interest. As result, the development of methodologies to facilitate the management process during the operation phase of a virtual enterprise (VE) is an important element for the wide adoption of this paradigm. Departing from a brief presentation of the Theory of Constraints this paper introduces an approach of these concepts to collaborative networks and discusses its potential application in the context of a (VE). To conclude, experimental results based on data from a collaborative network are presented and discussed.
\end{abstract}

\section{INTRODUCTION}

The business environment has changed radically during the last years and new changes will certainly continue (Abreu and Camarinha-Matos, 2006).

According to Penã and Arroyabe (Penã and Arroyabe, 2002) there are three environmental factors that have had the most decisive influence to encourage collaboration among organizations.

The first is economic globalisation. The world economy at the beginning of the twenty-first century is experiencing one of its moments of its greatest dynamism and change. This dynamism is reflected in the growing interdependence of markets for goods, services and production factors.

The second factor is the increase of business uncertainty. The speed in which changes are occurring in the economic world is introducing great uncertainty, especially in business areas where constant transformations, that are often difficult to predict, resulting from reductions in technological and product cycles, from improvements in productive processes and so on, are demanding greater follow-up capacity from enterprises in order to adapt to the new surrounding conditions.

Finally, the third feature is the high level of competitive rivalry. The increased customer requirements and market saturation are constantly obliging the enterprises to dig deeper in their search for competitive advantages in order to improve their position in the market. As a result, there is a tendency for enterprises to concentrate on know-how, or on those aspects of added value chain that they really dominate.

Consequently, the traditional forms of inter-organizational co-work such as outsourcing, spin-off, franchises, joint venture, consortium, etc, are changing for a 
new form of collaborative environments supported by the continuous advances in information and communication technologies. Examples of these later developments are advanced and highly integrated supply chains, virtual enterprises/virtual organizations, virtual (professional) communities and value constellations, etc., where most of these collaborative environments imply some kind of organizational configuration of activities within the environment and its constituents.

On the other hand, in most literature about collaboration there is an assumption that collaboration networks can bring a clear intuitive advantages to its members and can even represent a survival factor in turbulent socio-economic scenarios. On the basis of these expectations are, among others, the following factors among others: sharing of risks and resources, joining of complementary skills and capacities, acquisition of an apparently higher dimension, access to new / wider markets and new knowledge (Camarinha-Matos and Abreu, 2004).

However, in spite of these advantages, it is also frequently mentioned that collaboration also involves additional overheads (e.g. transaction costs) (Williamson, 1985) and several risks and the lack of tools tailed to support management activities is an obstacle for a wider acceptance of this paradigm.

In order to contribute for the development of a tool that supports the management activities in a collaborative context, the suggested approach doesn't want to "reinvent the wheel" but rather to adapt and take into account possible contributions from others disciplines. However it's necessary to take into account that these approaches and corresponding tools have been developed for different contexts (Camarinha-Matos and Abreu, 2003). Therefore their application to collaborative networks requires assessment, adaptations, and further developments. Furthermore, there are a large number of different perspectives that cannot be covered by a single theory or single modeling approach.

This paper introduces some discussion about the applications of the Theory of Constraints' concepts in collaborative networks and discusses its potential application in the context of virtual enterprises.

\section{THE THEORY OF CONSTRAINTS}

The Theory of Constraints (TOC) introduced a new perspective on system management that is distint from the classical approaches. According to this approach the systems should be managed taking into account its main constraint and the improvement of the system requires its improvement or elimination.

The TOC was developed initially for Production Systems (Goldratt and Cox, 1992), and later for Project Management (Goldratt, 1997) and more recently has also been applied to Strategic Planning (Dettmer, 2003).

The TOC can be seen as a prescriptive theory that promotes an increase of the system's performance based on an identification and subsequent improvement of the main constraint of the system (which can be applied to an organization or to a network of organizations) in a systematic, successive and continuous way considering several conceptual principles (Dettmer, 1997), from which the following ones can be pointed out:

- Systems can be viewed as a chain of interrelated elements in which the global performance is constrainted by its weekest link. 
- Local optimization does not guarantee global optimization.

- Optimal solutions tend to deteriorate as the system's environement changes.

- System's constraints can be physical or policy, these last ones are more difficult to identify, change or eliminate but when achieved they usually result on a larger degree of system improvement.

- To know what to change in systems requires the understanding of their current reality and goals, as well as the magnitude and direction of the difference between them.

- Many of the undesired effects (UDEs) in systems are manisfestations of core problems, that when solved, eliminate all resulting UDEs, althought the individual eliminations of UDE's does not eliminate the core problem.

- Core problems manifest themselves through UDEs linked by a network of cause-effect and are perpetuated by hidden or underlying conflicts.

- Solution of core problems requires challenging the assumptions underlying each conflict and at least one assumption must be invalidated to solve the conflict.

- Solutions tend to create resistance for further change, that is why inertia shoud be combated.

As result, TOC is being seen as a management philosophy where the system is managed from a global perspective. The continuous improvement is obtained from the management of the system elements' interactions where the individual performance of each member is defined by taking into account the main system constraint also called the weakest link.

TOC includes several elements that can be classified in four domains (Tenera, 2006), as shown in the Figure 1.

\begin{tabular}{|c|c|c|}
\hline & Prescriptive Component & Thinking Component \\
\hline & 1. Concepts and Principles & 2. Logical Thinking Tools \\
\hline 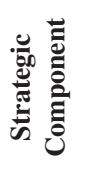 & $\begin{array}{ll}\text { - } & \text { Main Concepts } \\
\text { - } & \text { General Principles } \\
& \text { (Fundamental questions and } \\
& \text { focusing steps) } \\
& \text { Layers of Resistance to change }\end{array}$ & $\begin{array}{ll}\text { - } & \text { Thinking Tools (CRT, CRD, } \\
\text { FRT, NBR, PRT, TT) } \\
\text { - } \quad \text { Categories of Legitimate } \\
\text { Reservation (CLR) }\end{array}$ \\
\hline \multirow[b]{2}{*}{ 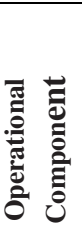 } & 3. Specfic Solutions & 4. Performance Measurements \\
\hline & $\begin{array}{ll}- & \text { Drum-Buffer-Rope (DBR) } \\
- & \text { Critical Chain (CC) } \\
- & \text { Buffer Management (BM) } \\
- & \text { V-A-T Analysis }\end{array}$ & $\begin{array}{ll}- & \text { Throughput, T } \\
- & \text { Inventory, I } \\
- & \text { Operating expense, OE }\end{array}$ \\
\hline
\end{tabular}

Figure 1 - TOC Schematic Summary

These four domains result from crossing two main variables: the scope of the problem which can be more strategic or more operational and the type of approach used to analyse the system which can have a more prescriptive or thinking nature. As result, the domains can be identified as: 1. Main concepts and general principles, 
which give the general guidelines of TOC logic in any system, 2. Logical thinking tools to identify core problems and solutions, 3. Solutions for specific environments and finally 4. Evaluation performance measurements to evalute systems performance.

In the domain of the specific solutions (3.), TOC proposed the Drum-BufferRope approach to improve production system results which promotes the introdution of material Buffers to maximize the performance of the constrainted resource (the Drum) and better sincronization of the production flows through alert or information mechanisms (Rope) that will give the information needed to manage the production flow taking into account the buffers consumption (Goldratt and Cox, 1992). Similar approach in Project Management results in the critical chain (CC) as the drum of the project (activities linked by technical and resource dependencies that defined the project duration) and a proposed solution to manage projects best known as Critical Chain Project Management (CCPM) which will be presented in next section.

\section{THE CRITICAL CHAIN APPROACH}

The Critical Chain (CC) concepts were introduced by Goldratt in 1997 as an alternative approach to classical ones in Project Management (Goldratt, 1997) like PERT (Program Evaluation and Review Technique) or CPM (Critical Path Method). Best known as CCPM, the solution proposed by this approach incorporates technical elements for planning, schedule and control of project networks, and operational elements which include human actions and behaviors like the roadrunner mentality.

According to CCPM the network planning and schedule process should be developed in four fundamental phases:

\section{a) Network Building}

The network is built in two phases: first the network is created using an inverse logic i.e. from the last to the first activity. During this phase the project management team should identify the deliverable associated to each activity, the prerequisites and assumptions assumed. During the second phase the classical direct logic is used to verify and reformulate if necessary the activities relations identified in the first phase. The output of this approach will be an activity on node (AON) network with preferably Finish-to-Start (FS) activities and assumed resource constraints.

\section{b) Activity Durations Estimation}

The activity duration is probabilistic (Goldratt, 1997) and at least two estimations have to be made: a target duration (generally median or average duration) and a pessimistic duration.

\section{c) Critical Chain Identification}

The Critical Chain (CC) is the set of activities scheduled according to a As Late as Possible (ALAP) process that defines the project duration, based on activity durations, technical and resource dependencies. 


\section{d) Time Buffers Insertion and Network Scheduling}

For each activity, CCPM builds schedules using target duration tight, Finished to Start (FS) dependencies and an As Late As Possible (ALAP) logic with buffers. The time buffers are time blocks incorporated on schedule in special points of the network to reduce the impact of duration variability of the activities on network, i.e a safety margin is aggregated at the end of the project, where it acts as a protection of the project due date, called Project Buffer (PB), and also in Feeding Buffers (FB), placed whenever a non-critical activity joins the critical chain, to protect critical activities against variations of the feeding chains.

Figure 2 illustrates a very simplified AON network with six activities (from A1 to A6) where the bar size defines the activity duration.

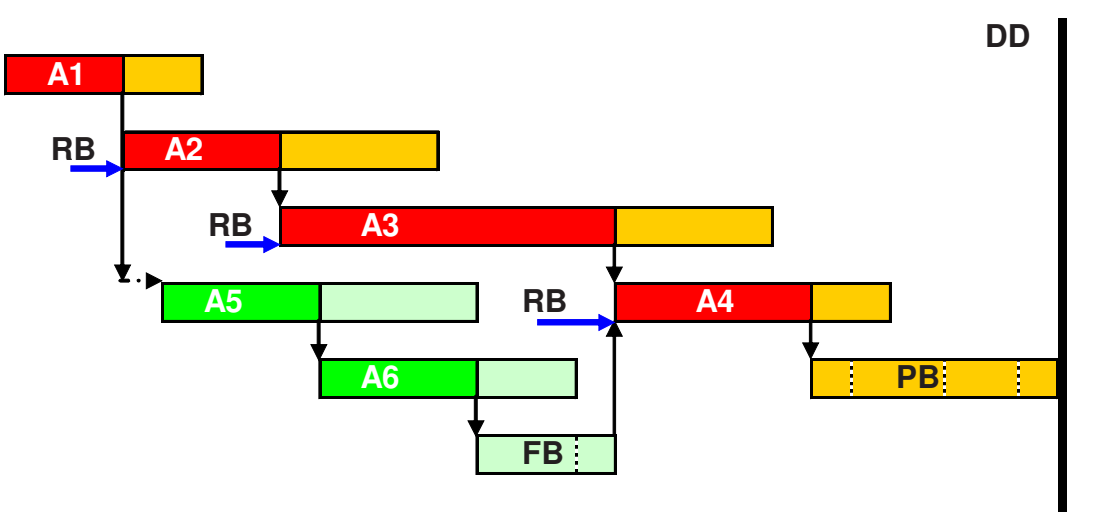

Figure 2 - CCPM Scheduling

In Figure 2 the $\mathrm{CC}$ is given by path $\mathrm{A} 1, \mathrm{~A} 2, \mathrm{~A} 3, \mathrm{~A} 4$. To protect the project Due Date (DD) against $\mathrm{CC}$ duration variability a time buffer designed by Project Buffer (PB) is introduced after the last activity of the project. The PB is set to work as a time pillow or damper against schedule variability of critical chain activities as well as a visual register of the time impact of the randomness occurred in the network activities. This register is used as the control tool of the project execution and is intended to be efficient, focused and global.

To protect the CC from the variability of non critical activities durations (A5 e A6) another time buffer is inserted in arcs that connects non critical activities and critical activities. This type of buffer is designated by Feeding Buffers (FB).

To size the buffers Goldratt suggested a practical and simple cut of $50 \%$ in the pessimistic duration and schedule a buffer of $50 \%$ of the trimmed duration of the chain with $n$ activities. After Goldratt's proposal of the critical chain principles of scheduling and management for projects (Goldratt, 1997) several other authors (Newbold, 1998; Hoel and Taylor, 1999; Leach, 2000; Shou and Yeo, 2000; Park and Pena-Mora, 2004; Tenera and Cruz-Machado, 2007) have proposed different methods for sizing projects and feeding buffers. 


\section{POTENTIAL APPLICATION IN CN CONTEXT}

The concept of virtual enterprise is considered by a growing number of authors as a temporary network of enterprises, that is formed to explore a business opportunity; a Project is also viewed as "a temporary endeavor undertaken to create a unique product, service or result" (Project Management Institute, 2004) that can be modeled by a network of activities.

Assuming that, a virtual enterprise can be managed through a project network where the activities are replaced by enterprises and the links between activities represent dependences among enterprises, both concepts can be related as illustrated in Figure 3.

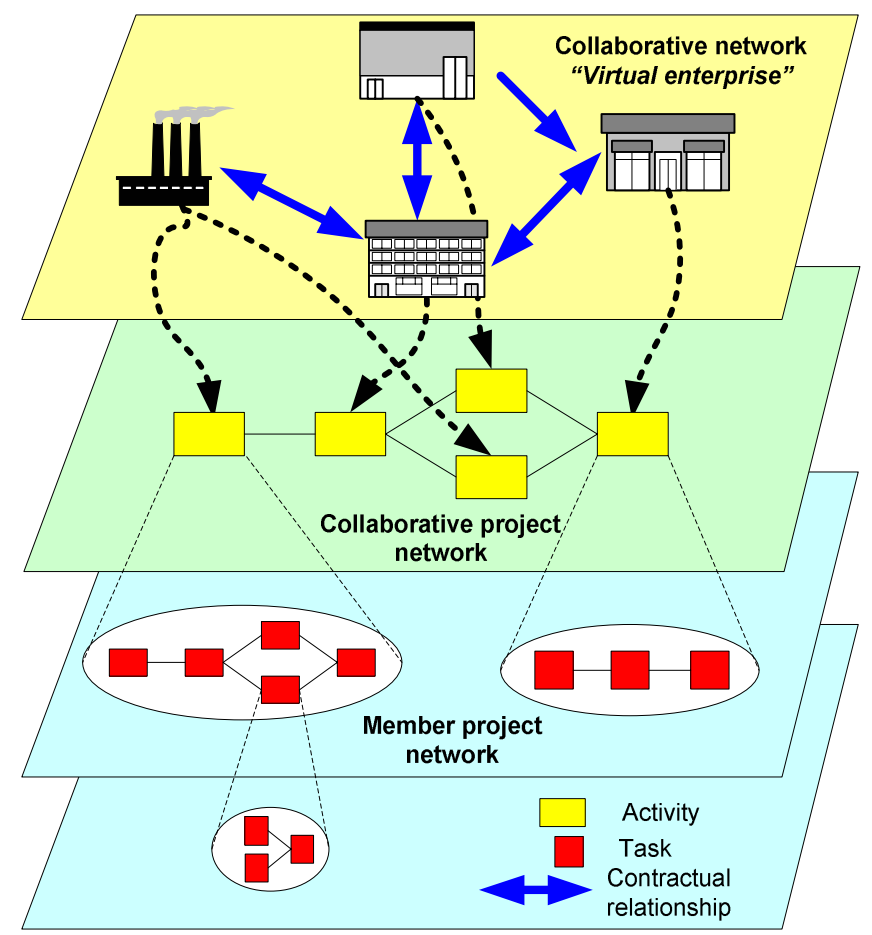

Figure 3 - Relation between project network and virtual enterprise

However, the success of this approach requires the existence of mechanisms that act as incentives for collaboration and punish the infractors. Futhermore, the partners involved in a collaborative network must provide to the VE coordinater, reliable information in useful time during the execution of the project; as well as, when was necessary to participate effectively in the recovery of delays. 


\section{EXPERIMENTAL RESULTS}

The approach described earlier was applied in a major civil construction project, which comprised the construction of two twins towers at the municipality of Lisbon. According to the contract agreement the main goal was to build the towers within the time settled. The contractor was in charge for the planning, scheduling and construction. In order to built the towers the contractor worked with several subcontractors, resulting in a collaborative network with different entities and activities to develop. However, the number of resources involved in the construction of the first tower was greater than in the second tower.

In terms of management tools, the first tower was managed applying classical tools for project management while the second one was managed based on a CCPM collaborative approach.

Based on this approach the process of planning and scheduling the resources was applied at macro level where each member of the collaborative network had a set of tasks and sequences which were not programmed in the baseline of the collaborative project network but at the company project level.

After the identification of the critical chain of the collaborative project network the time buffers, BfS, were introduced. The size of all time buffers was calculated according to SMC method (which stands for Simulação para a Melhoria da Calendarização). The underlying logic of the proposed method (Tenera, 2006) is to size buffers addressing the risk using a simulation technique (Monte Carlo) of overrun the scheduled date of last activities of the chains (see Figure 4) considering the project schedule in the ALAP logic, as proposed in CCPM methodology.

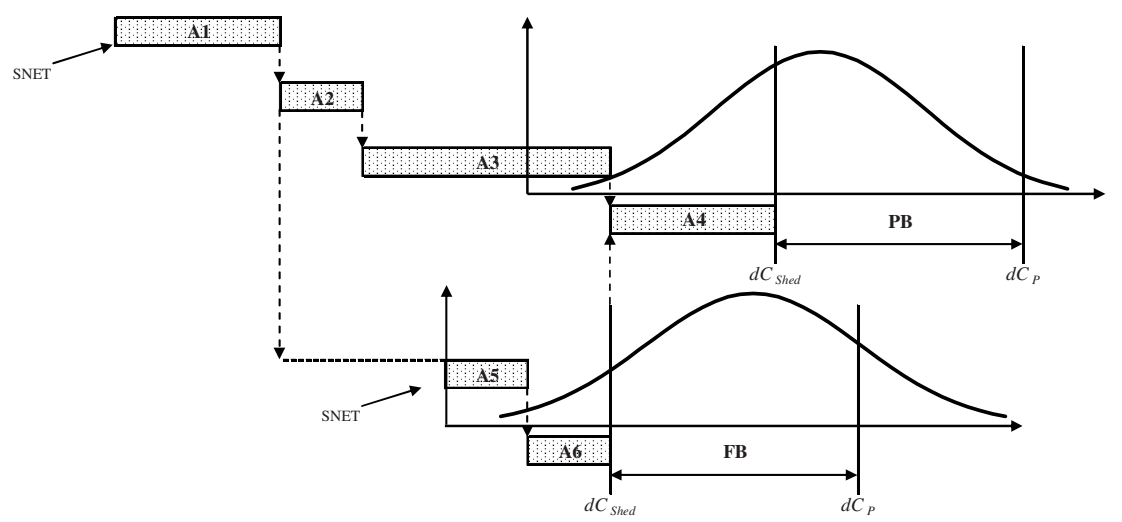

Figure 4 - SMC Logic

Considering, as an example, the very simple project network introduced earlier (Figure 2) with activities, $A_{i}$, interrelated with Finish to Start (FS) activities relations, schedule in an As Late As Possible (ALAP) logic assuming target durations for each activity. From Figure 4 it was possible to identify activities A1, 
$\mathrm{A} 2, \mathrm{~A} 3 \mathrm{e} \mathrm{A} 4$ as the critical activities of the project and activities A5and A6, as non critical activities.

Assuming the ALAP scheduling logic of CCPM, the start of non critical activities, not depending from preceding activities conclusion, should not start before their ALAP schedule start date (with buffers included). Time buffers should be sized using: an assumed risk level for time overrun of the last activity of the critical chain for project buffer ( $\mathrm{PB}$ ) sizing purpose, and; a risk level for time overrun of end schedule dates of non critical activities converging to critical activities in sizing feeding buffers (FB).

To define the risk of overrun schedule activities end time, Monte Carlo Simulation was chosen as the simulation tool; it is a well known tool, and it has been used in project management risk analysis (Law and Kelton, 1991).

The difference between the simulated end date of these activities, associated with a chosen confidence level $\left(d C_{p}\right)$, and the schedule date $\left(d C_{S h e d}\right)$, will be the time buffer to schedule (1). This buffer is intended to reduce the impact of non critical activities in the critical chain and to protect the project end date against variability. With this in mind, feeding buffers insertion can require the creation of a gap on the critical chain, as the duration variability of non critical chain should not delay the schedule start of critical chain activities (Goldratt, 1997) in order to improve the stability of the critical chain.

$$
B f S=d C_{p}-d C_{\text {Shed }}
$$

During the execution of the project the scheduling update process was done considering not only the conclusion percentage of the undergoing activities but also using estimated and approved activity remaining durations. If needed, to reduce project buffer consumption the target duration was also changed in activities immediately following the undergoing activities. For that each member of the collaborative project network has to evaluate and if required, reschedule his member project network according to the changes approved for the collaborative network, in site reunions.

If we compare the activities baseline durations of the collaborative network and the real durations, one can see that the majority of the durations were not respected (Figure 5).

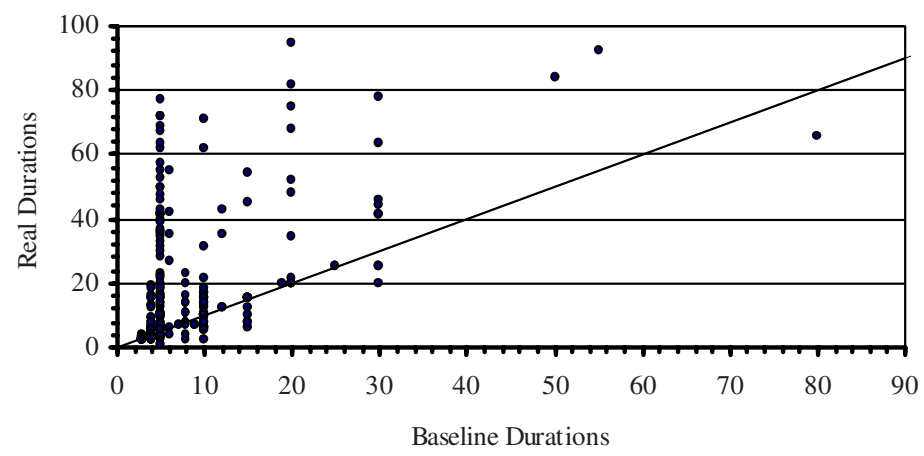

Figure 5 - Real durations versus Baseline durations 
However, comparing the scheduled durations of the collaborative project network with the real ones, it can be seen that there is a greater linearity relation (Figure 6). These results show a more aligned schedules durations with the real activities durations, as a result of the CCPM management process used.

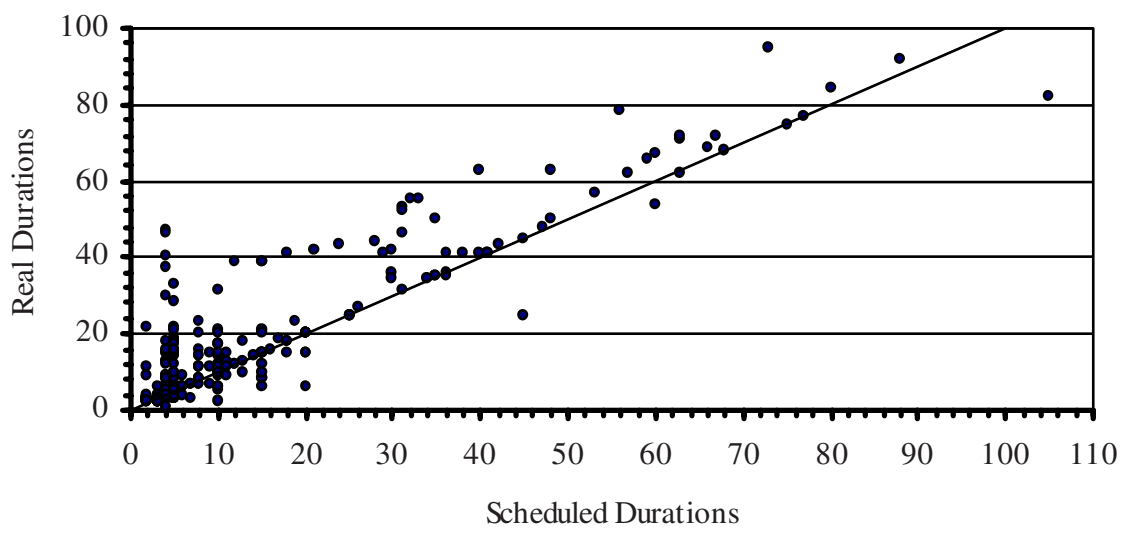

Figure 6 - Real durations versus Schedule durations

As illustrated in Figure 7 and in opposition to the First tower, managed according to traditional approaches, the application of the CCPM approach allowed to anticipate the schedule conclusion of the CCPM tower, managed using the proposed approach.

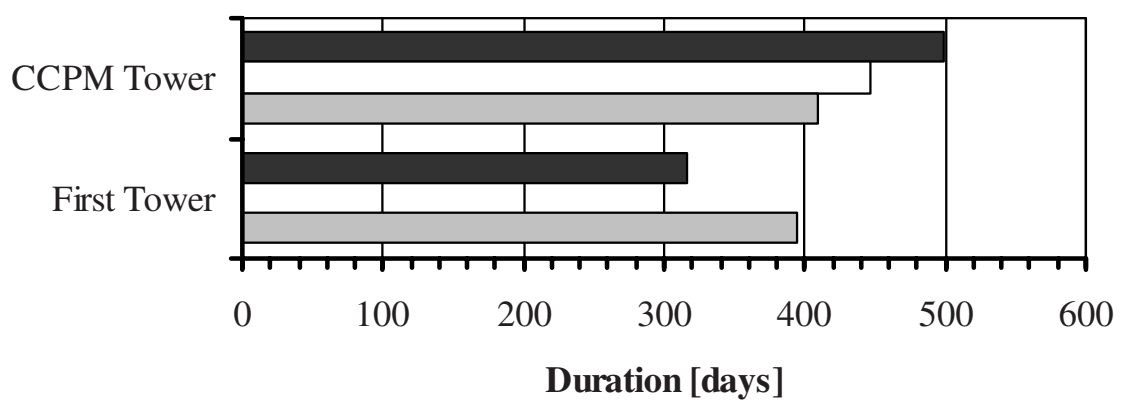

Deterministic Baseline $\square$ CCPM Baseline $\square$ Real

Figure 7 - Final phase durations of First Tower and CCPM Tower

\section{CONCLUSIONS}

Forms of collaboration have changed over the years and have become increasingly visible and complex. However, the development of models and tools that support management activities in collaborative environments will not only help to better 
understand the area, but also for a wide adoption of the collaborative networks paradigm in its various manifestation forms.

Some preliminary steps in this direction, inspired in critical chain concepts were presented. Initial results illustrate the applicability of the suggested approach. Further steps are necessary towards the elaboration of a robust tool as well as its validation.

\section{REFERENCES}

1. A. Abreu and L. M. Camarinha-Matos, "On the role of value systems and reciprocity in collaborative environments" in IFIP International Federation for Information Processing vol 224, L. M. Camarinha-Matos, H. Afsarmanesh, and M. Ollus, Eds. Boston: Springer, 2006, pp. 273-284.

2. N.A Penã, and J.C.F.Arroyabe, Business Cooperation, Palgrave:Macmillan, 2002.

3. L. M. Camarinha-Matos and A. Abreu, A contribution to understand collaboration benefits, in Emerging Solutions for Future Manufacturing Systems, L. M. Camarinha-Matos, Ed.: Springer, 2004.

4. Williamson, O. E. (1985). The Economic Institutions of Capitalism: Firms, Markets, Relational Contracting, New York: Free Press.

5. L.M. Camarinha-Matos and A. Abreu,"Towards a Foundation for Virtual Organizations," in Proc. of Business Excellence I: Performance Measures, Benchmarking and Best Practices in New Economy. Braga, 2003, pp. 647-652.

6. E.M. Goldratt, and J. Cox, The Goal: An Ongoing Improvement Process ( $2^{\mathrm{a}}$ ed.), North River Press, Great Barrington, Mass., 1992.

7. Goldratt, E. M. (1997). Critical Chain. Great Barrington, MA, EUA: North River Press.

8. H.W. Dettmer, Strategic Navigation: A Systems Approach to Business Strategy, ASQ Quality Press, Milwaukee, Wisc., 2003.

9. H.W. Dettmer, Goldratt's Theory of Constraints: A System Approach to Continuous Improvement, Milwaukee WI: ASQ Quality Press,. 1997.

10. A. Tenera, "Contribution for the Improvement of Uncertainty Management in Project Duration through Theory of Constraints," (in Portuguese), Ph.D. dissertation, Dept. Mech. and Industrial Eng., University Nova of Lisboa, 2006.

11. Newbold, R. C. (1998). Project management in the fast lane. Boca Raton, FL, EUA: St. Lucie Press.

12. Hoel, K., \& Taylor, S. G. (1999). Quantifying buffers for project schedules. Production and Inventory Management Journal, 40, 43-47.

13. Leach, L. (2000). Critical Chain Project Management. Norwood, MA, EUA: Artech House.

14. Shou, Y., \& Yeo, K. T. (2000, November 12-15). Estimation of project buffers in critical chain project management. IEEE International Conference on Management of Innovation and Technology, Singapore.

15. Park, M., \& Pena-Mora, F. (2004). Reliability buffering for construction projects. Journal of Construction Engineering and Management, 130, 626-637.

16. Tenera, A., \& Cruz-Machado, V. (2007). Critical chain project management: A new approach for time buffer sizing. in Proc. of the Institute of Industrial Engineering Annual Conference, Nashville.

17. Project Management Institute [PMI]. PMBOK® Guide. ANSI/PMI Standard 99-0012004, 2004, p.5.

18. Law, A. M., \& Kelton, D. (1991). Simulation Modeling and Analysis (2 ${ }^{\mathrm{a}}$ ed.). Singapure: McGraw-Hill. 